\title{
Hypopharyngeal Cancer pT4b TNM Finding v6
}

National Cancer Institute

\section{Source}

National Cancer Institute. Hypopharyngeal Cancer pT 4b TNM Finding v6. NCI Thesaurus. Code C64453.

Hypopharyngeal cancer with tumor invading prevertebral fascia, encasing carotid artery, or involving mediastinal structures. (from AJCC 6th Ed.) 